\title{
Prevalence and Characterization of Extended-Spectrum $\beta$ - Lactamase-Producing Escherichia coli and Klebsiella pneumoniae Isolated from Raw Vegetables Retailed in Southern Thailand
}

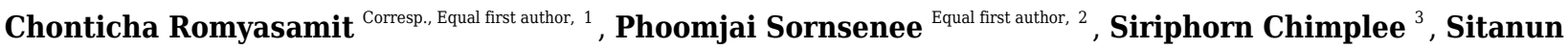 \\ Yuwalaksanakun $^{1}$, Dechawat Wongprot ${ }^{1}$, Phanvasri Saengsuwan ${ }^{3}$ \\ ${ }^{1}$ Department of Medical Technology, School of Allied Health Sciences, Walailak University, Nakhon Si Thammarat, Thailand \\ Department of Family and Preventive Medicine, Faculty of Medicine, Prince of Songkla University, Songkhla, Thailand \\ 3 Department of Biomedical Sciences and Biomedical Engineering, Faculty of Medicine, Prince of Songkla University, Songkhla, Thailand \\ Corresponding Author: Chonticha Romyasamit \\ Email address: chonticha.ro@wu.ac.th
}

Background. The increasing prevalence of broad-spectrum ampicillin-resistant and third-generation cephalosporin-resistant Enterobacteriaceae, particularly Escherichia coli and Klebsiella pneumoniae, has become a global concern, with its clinical impacts on both human and veterinary medicine. This study examined the prevalence, antimicrobial susceptibility, and molecular genetic features of extendedspectrum $\beta$-lactamase (ESBL)-producing $E$. coli and $K$. pneumoniae isolates from 10 types of raw vegetables.

Methods. In total, 305 samples were collected from 9 markets in Nakhon Si Thammarat, Thailand, in 2020.

Results. ESBL-producing E. coli and K. pneumoniae isolates were found in 14 of the 305 samples obtained from 7 out of 10 types of vegetables (4.6\% of the total). Further, $14 \mathrm{ESBL}$-producing $E$. coli $(\mathrm{n}=$ $5 / 14)$ and $K$. pneumoniae isolates $(n=9 / 14)(1.6 \%$ and $3.0 \%$, respectively) were highly sensitive to $\beta$ lactam/carbapenem antibiotics (imipenem, 100\%). ESBL-producing $E$. coli $(\mathrm{n}=4)$ and $K$. pneumoniae isolates $(n=8)$ were also sensitive to non- $\beta$-lactam aminoglycosides (amikacin, $80.00 \%$ and $88.89 \%$, respectively). ESBL producers were most resistant to $\beta$-lactam antibiotics, including ampicillin (85.71\%) and the cephalosporins cefotaxime and ceftazidime (64.29\%). The most frequently detected gene in ESBL-producing $E$. coli and $K$. pneumoniae was bla $a_{S H V}$. However, two ESBL-producing $E$. coli isolates also carried three other ESBL-encoding variants, bla $a_{T E M}, b / a_{C T X-M 1}, b / a_{G E S}$ and bla $a_{T E M}, b l a_{S H V}$, bla $a_{C T X-M 9}$, which may be due to their association with food chains and humans.

Discussion. Indeed, our results suggest that raw vegetables are an important source of ESBL-resistant $E$. coli and $K$. pneumoniae, which are potentially transmittable to humans via raw vegetable intake. 
1 Prevalence and Characterization of Extended-Spectrum $\boldsymbol{\beta}$-Lactamase-Producing

2 Escherichia coli and Klebsiella pneumoniae Isolated from Raw Vegetables Retailed in

3 Southern Thailand

4

5

6

Chonticha Romyasamit ${ }^{1+*}$, Phoomjai Sornsenee ${ }^{2+}$, Siriphorn Chimplee ${ }^{3}$, Sitanun

Yuwalaksanakun $^{1}$, Dechawat Wongprot ${ }^{1}$, Phanvasri Saengsuwan ${ }^{3}$

${ }^{1}$ Department of Medical Technology, School of Allied Health Sciences, Walailak University, Nakhon Si Thammarat 80161, Thailand

${ }^{2}$ Department of Family and Preventive Medicine, Faculty of Medicine, Prince of Songkla University, Songkhla 90110, Thailand

${ }^{3}$ Department of Biomedical Sciences and Biomedical Engineering, Faculty of Medicine, Prince of Songkla University, Hat Yai, Songkhla, 90110, Thailand

${ }^{+}$Co-first author

Corresponding Author:

Chonticha Romyasamit

222 Thaiburi, Tha Sala, Nakhon Si Thammarat, 80161, Thailand

Email address: chonticha.ro@wu.ac.th

\section{Abstract}

Background. The increasing prevalence of broad-spectrum ampicillin-resistant and thirdgeneration cephalosporin-resistant Enterobacteriaceae, particularly Escherichia coli and Klebsiella pneumoniae, has become a global concern, with its clinical impacts on both human and veterinary medicine. This study examined the prevalence, antimicrobial susceptibility, and molecular genetic features of extended-spectrum $\beta$-lactamase (ESBL)-producing $E$. coli and $K$. pneumoniae isolates from 10 types of raw vegetables.

Methods. In total, 305 samples were collected from 9 markets in Nakhon Si Thammarat, Thailand, in 2020.

Results. ESBL-producing E. coli and K. pneumoniae isolates were found in 14 of the 305 samples obtained from 7 out of 10 types of vegetables (4.6\% of the total). Further, 14 ESBLproducing $E$. coli $(\mathrm{n}=5 / 14)$ and $K$. pneumoniae isolates $(\mathrm{n}=9 / 14)(1.6 \%$ and $3.0 \%$, respectively) were highly sensitive to $\beta$-lactam/carbapenem antibiotics (imipenem, $100 \%$ ). ESBL-producing E. coli $(\mathrm{n}=4)$ and $K$. pneumoniae isolates $(\mathrm{n}=8)$ were also sensitive to non- $\beta$ lactam aminoglycosides (amikacin, $80.00 \%$ and $88.89 \%$, respectively). ESBL producers were most resistant to $\beta$-lactam antibiotics, including ampicillin $(85.71 \%)$ and the cephalosporins cefotaxime and ceftazidime (64.29\%). The most frequently detected gene in ESBL-producing $E$. coli and K. pneumoniae was bla $a_{S H V}$. However, two ESBL-producing E. coli isolates also carried 
three other ESBL-encoding variants, bla $_{T E M}$, bla $_{C T X-M I}$, bla $_{G E S}$ and bla $_{T E M}$, bla $_{S H V}$, bla $_{C T X-M 9}$, which may be due to their association with food chains and humans.

Discussion. Indeed, our results suggest that raw vegetables are an important source of ESBLresistant $E$. coli and $K$. pneumoniae, which are potentially transmittable to humans via raw vegetable intake.

\section{Introduction}

Extended-spectrum $\beta$-lactamase (ESBL)-producing Enterobacteriaceae, particularly Escherichia coli and Klebsiella pneumoniae, produce nosocomial infections in patients and can also affect communities of heathy individuals (1-3). The increasing prevalence of ESBLproducing strains has increased the possibility of the development of $\beta$-lactam antibiotic resistance $(2,4)$. This will exacerbate global public health problems and thus requires resolution. Apart from nosocomial infections, ESBL-producing E. coli and K. pneumoniae have emerged as community infection concerns, causing severe infections, such as urinary and respiratory tract infections and bacteremia $(2,4,5)$. Therefore, it is crucial to identify the sources of ESBLproducing $E$. coli and $K$. pneumoniae. In the last decade, the prevalence of resistance to aminoglycosides, sulfonamides, fluoroquinolones, and cephalosporins in ESBL-producing $E$. coli and $K$. pneumoniae has increased considerably, limiting the treatment of infections caused by these bacteria $(6,7)$. Currently, more than 350 variants of ESBL have been identified using amino acid sequence comparisons and are categorized into 9 distinct families (8). The four most common ESBLs, namely $b_{C T X-M}$, bla $_{T E M}$, bla $_{S H V}$, and $O X A$, are found in Enterobacteriaceae species (9). bla $a_{T E M}$ is predominant in China, whereas $b l a_{S H V}$ is the predominant variant of ESBLs in Canada. Moreover, $b l a_{C T X-M}$ is predominant in various countries such as Spain, the United States of America, and the United Kingdom (8). In a previous study, three $b l a_{C T X-M-15}$ variants, one $b l a_{C T X-M-I}$ variant, two $b l a_{C T X-M-9}$ variants, and one bla $_{S H V}$ variant were found in retail raw vegetables (10).

Raw vegetables are considered exceptional human food due to their convenience for uncooked consumption (11). In addition, consumers deem vegetables more advantageous to health; thus, there has been a noted increase in the consumption of vegetables instead of foods produced from animals (11). However, uncooked vegetables can have high levels of microbial contamination, which in turn could lead to a high rate of cross-contamination events (E. coli and K. pneumoniae-vegetables-human) $(3,12-14)$. In fact, it has been reported that ESBL-producing bacteria could be present in fresh vegetables such as iceberg lettuce, spinach, and tomato (15, 16). However, studies on the incidence of ESL-producing Enterobacteriaceae in fresh vegetables, which are commonly found and consumed in tropical countries such as Thailand, remain to be limited.

Previously, numerous studies have reported the prevalence of ESBL-producing Enterobacteriaceae bacteria; in particular, E. coli and K. pneumoniae have been found in human and animal foods and in food-producing animals $(3,17-26)$. The isolation of both ESBLproducing species from vegetable samples has also been described in various studies $(3,12,15$, 16, 22, 26-29). Although the prevalence and role of ESBL producers in vegetables, such as cabbages, cucumbers, tomatoes, coriander, and lettuce, which are cultivated ubiquitously worldwide, have been examined, there have been few studies on vegetables (yardlong beans, 
winged beans, basil, eggplant, and young cashew leaves) that are specifically found in Thailand and tropical countries, and are frequently consumed in Southern Thailand. Thus, this study aimed to examine the prevalence and characteristics of ESBL-producing E. coli and K. pneumoniae in common raw vegetables found in Southern Thailand. The associations between ESBL-encoding genes and ESBL-producing strains were characterized to correlate data with those previously obtained in isolates from other food and clinical sources.

\section{Materials \& Methods}

Vegetable collection

In total, 305 samples derived from 10 common edible vegetables were included in this analysis: Thai yardlong beans (34), Thai eggplant (44), winged bean (25), young cashew leaves (20), Thai basil (36), cabbage (21), cucumber (36), tomato (31), long coriander (32), and lettuce (26). These were bought randomly between September 2020 and October 2020 from four and five local retail markets in Tha Sala and Mueang districts, respectively, in Nakhon Si Thammarat, Thailand. After purchase, the vegetable samples were collected in sterile containers, maintained at $4^{\circ} \mathrm{C}$, and tested within $24 \mathrm{~h}$.

\section{Isolation and Identification of ESBL-producing E. coli and K. pneumoniae}

About $25 \mathrm{~g}$ of each sample was weighed, suspended in $225 \mathrm{~mL}$ of $0.1 \%$ buffered peptone water (Oxoid, Hampshire, UK), and incubated at $37^{\circ} \mathrm{C}$ for $24 \mathrm{~h}$. These microbial enrichments were streaked onto ESBL-selective agar (HiMedia Laboratories, Mumbai, India), followed by incubation at $37^{\circ} \mathrm{C}$ for $24 \mathrm{~h}$ under aerobic conditions to enable morphological and color-coded distinction of individual ESBL-producing Enterobacteriaceae isolates according to the specifications of the producer. Suspected colonies of the Enterobacteriaceae E. coli (pink to purple) and $K$. pneumoniae (bluish green) were picked from each selective plate and streaked onto nutrient agar (Oxoid) at $37^{\circ} \mathrm{C}$ for $24 \mathrm{~h}$, followed by biochemical identification using Vitek2 (bioMérieux, Marcy 1'Etoile, France). All the E. coli and K. pneumoniae isolates were then identified and confirmed by matrix-assisted laser desorption ionization/time-of-flight mass spectrometry (MADLI-TOF MS) (30). All the confirmed isolates were stored at $2^{\circ} \mathrm{C}-8^{\circ} \mathrm{C}$ until antimicrobial drug susceptibility testing and evaluation of ESBL production.

\section{Screening of presumptive ESBL-producing isolates}

The standard disk diffusion method was performed by placing $\beta$-lactam ring drugs ceftazidime (CAZ) $(30 \mu \mathrm{g})$ and cefotaxime (CTX) $(30 \mu \mathrm{g})$ on disks. The amount of bacteria was adjusted by $0.5 \mathrm{McFarland}$ standard, and the suspension was inoculated onto Mueller-Hinton agar (MHA; Oxoid) using a sterile cotton swab. Thereafter, the drug disks were placed on inoculated plates, followed by incubation at $37^{\circ} \mathrm{C}$ for $24 \mathrm{~h}$. Isolates presenting an inhibition zone to $\mathrm{CTX}(\leq 27 \mathrm{~mm})$ and CAZ $(\leq 22 \mathrm{~mm})$ around the disks were regarded as presumptive ESBLproducing strains, based on Clinical and Laboratory Standards Institute (CLSI) 2019 guidelines (31). 
123

124

125

126

127

128

129

130

131

132

133

134

135

136

137

138

139

140

141

142

143

144

145

146

147

148

149

150

151

152

153

154

155

156

157

158

159

160

161

\section{Confirmation of ESBL-producing isolates}

The double-disk synergy method was performed to confirm ESBL production in the presumptive positive isolates. E. coli and $K$. pneumoniae suspensions were placed onto MHA. Then, 30- $\mu \mathrm{g}$ CTX and CAZ disks were placed in the center of the plate, followed by placing CTX and CAZ plus clavulanic acid $(30 / 10 \mu \mathrm{g})$ disks at a distance of $20 \mathrm{~mm}$ from the central disk in the same plate (CLSI 2019). All plates were incubated at $37^{\circ} \mathrm{C}$ for $24 \mathrm{~h}$. Isolates were considered ESBL producers when the zone of inhibition with CTX or CAZ disk with clavulanic acid was increased by $\geq 5 \mathrm{~mm}$ in comparison to that by CTX or CAZ alone.

\section{Antibiotic sensitivity test}

To assess the antibiotic sensitivity profile of ESBL-producing E. coli and K. pneumoniae were isolated from the vegetables, antibiotic sensitivity test was conducted according to the methods in the CLSI 2019 guidelines (31) and Abayneh M., et al. (2019) (20), with modifications isolates were suspended and inoculated onto MHA, and then $\beta$-lactam ring antibiotic disks were placed on the culture plates. These plates contained $10 \mu \mathrm{g}$ each of ampicillin (AMP), imipenem (IPM), meropenem (MEM), tetracycline (TE), gentamicin (CN), or cefpodoxime (CPD) or $30 \mu \mathrm{g}$ each of amikacin (AK), CTX, ceftriaxone (CRO), CAZ, or aztreonam (ATM) and were incubated at $37^{\circ} \mathrm{C}$ thereafter. The inhibited zone was measured using calipers according to CLSI 2019 guidelines. K. pneumoniae ATCC 700603 and E. coli ATCC 25922 were used as positive and negative control strains. Multidrug resistance (MDR) is defined as resistance to at least 1 agent in $\geq 3$ antimicrobial classes.

\section{DNA extraction}

DNA extraction was performed using AccuPrep Genomic DNA Extraction Kit (Bioneer, South Korea). Briefly, the bacterial suspension was centrifuged at 1,200 rpm, and the supernatant was removed. The pellet was washed with phosphate-buffered saline. After centrifugation, the supernatant was removed, and $20 \mu \mathrm{L}$ of proteinase $\mathrm{K}$ was added. Tris-EDTA (TE) buffer was added to the DNA, and the final solution was adjusted for direct use as a polymerase chain reaction $(\mathrm{PCR})$ template.

\section{Genotypic characterization of ESBL-producing isolates}

Standard PCR was performed to screen the presence of 7 ESBL-encoding genes: bla $_{T E M}$

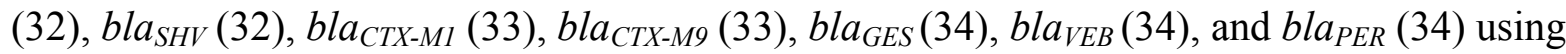
specific primers described in Table 1 . PCR reactions contained $1 \times$ buffer, $1.5 \mathrm{mM} \mathrm{MgCl}_{2}, 400$ $\mu \mathrm{M}$ dNTPs, $0.2 \mu \mathrm{M}$ each of the forward and reverse primers, $1 \mathrm{U}$ Taq polymerase, and $50 \mathrm{ng} / \mu \mathrm{L}$ DNA template. The PCR cycling conditions were dependent on the specific primers of the target gene as tabulated in Table 1. After PCR processing, PCR products were analyzed using agarose gel electrophoresis and sequenced on Applied Biosystems 3730XL (Macrogen, Seoul, Korea).

Peer) reviewing PDF | (2021:03:59057:2:0:NEW 21 Jun 2021) 
162 The sequences were then aligned with those in the NCBI database using the BLAST search tool

163 to determine sequence similarity (35).

164

165

166

167

168

169

170

171

172

173

174

175

176

177

178

179

180

181

182

183

184

185

186

187

188

189

190

191

192

193

194

195

196

197

198

199

200

201

Enterobacterial repetitive intergenic consensus-polymerase chain reaction (ERIC-PCR) and DNA amplification

The primers used for ERIC-PCR amplification were 5'-ATG TAA GCT CCT GGG GAT TCA C-3' (F) and 5'-AAG TAA GTG ACT GGG GTG AGC G-3' (R) (36-38). The total volume was $25 \mu \mathrm{L}$ for each reaction, including $2 \mu \mathrm{L}$ of template DNA $(50 \mathrm{ng} / \mu \mathrm{L})($ E. coli or $K$.

pneumoniae), $5.2 \mu \mathrm{L}$ of master mix, $0.25 \mu \mathrm{L}$ of forward and reverse primers $(100 \mu \mathrm{M})$, and 17.3

$\mu \mathrm{L}$ of deionized water. Subsequently, 30 cycles of denaturation $\left(95^{\circ} \mathrm{C}\right)$, annealing $\left(48^{\circ} \mathrm{C}\right)$, and

extension $\left(72^{\circ} \mathrm{C}\right)$ for $60 \mathrm{~s}$ each were performed using a thermocycler. Deionized water and

bacterial DNA of E. coli and K. pneumoniae strains were used as negative and positive controls, respectively.

Polymerase chain reaction products and gel electrophoresis

Polymerase chain reaction products and agarose gel electrophoresis were conducted according to the methods of Ranjbar R., et al. (2017) (38), with modifications. The amplicon was electrophoresed on a $1.5 \%$ agarose gel in $0.5 \mathrm{X}$ TBE electrophoresis buffer. A 100-base pair (bp) DNA ladder was used as a standard marker. The gel bands were observed under ultraviolet light.

Dendrogram and phylogenetic relationships

The DNA band pattern of the E. coli and K. pneumoniae samples obtained using gel electrophoresis of ERIC-PCR products was used as a generational structure for dendrogram analysis using BioNumerics version 7.1. For constructing a computerized dendrogram, the presence and absence of bands were presumed as 1 and 0 , respectively. The dendrogram was then designed using the unweighted pair-group method with arithmetic mean, which is categorized in clustering methodologies and is based on clustering analysis.

\section{Results}

Prevalence of ESBL-producing E. coli and K. pneumoniae

ESBL-producing E. coli and $K$. pneumoniae isolates were found in 14 of the 305 samples obtained from 7 out of 10 different vegetables (4.6\% of the total) (Table 2). The highest frequencies of both ESBL-producing bacterial species were found in Thai yardlong beans (3/34, $8.8 \%)$ and Thai basil $(3 / 36,8.3 \%)$, followed by winged beans $(2 / 25,8 \%)$, tomato $(2 / 31,6.5 \%)$, and cucumber $(2 / 36,5.6 \%)$, with minimal detection in long coriander $(1 / 32,3.1 \%)$ and Thai eggplant $(1 / 44,2.3 \%)$. ESBL-producing isolates were not detected in young cashew leaves, cabbage, or lettuce (Tables 2 and 3 ).

ESBL-producing $K$. pneumoniae isolates were found more frequently than $E$. coli isolates at $9 / 14(64.29 \%)$ and 5/14 (35.711\%), respectively. Nine $K$. pneumoniae isolates that produced ESBL were variously distributed in several vegetables in this study. Five of the nine $K$. 
202

203

204

205

206

207

208

209

210

211

212

213

214

215

pneumoniae isolates (11.11\%) were obtained from five different vegetables, i.e., Thai eggplant, winged beans, Thai basil, cucumber, and long coriander, and four of the nine isolates $(22 \%)$ were found in Thai yardlong beans and tomato (two each). Five ESBL-producing E. coli isolates were found in four different vegetables. Two isolates were most frequently found in Thai basil (40\%), and one isolate $(20 \%)$ was detected in each vegetable, including Thai yardlong beans, winged beans, and cucumber (Table 2).

Interestingly, both ESBL-producing E. coli and K. pneumoniae isolates were present in four specific vegetables, namely Thai yardlong beans, Thai basil, winged beans, and cucumber (Table 2). There was an equal proportion (1:1) of ESBL-producing E. coli and K. pneumoniae isolates in both winged beans and cucumber. Moreover, ESBL-producing E. coli and $K$. pneumoniae were frequently found in Thai basil and Thai yardlong beans. ESBL-producing $E$. coli isolates were detected more frequently in Thai basil than in Thai yardlong beans $(2: 1)$, which was in contrast to the proportion of ESBL-producing $K$. pneumoniae found in these vegetables (1:2) (Table 2).

Indeed, both ESBL-producing E. coli and K. pneumoniae were widely distributed in 7 out of 10 edible vegetables and were more frequently found in Thai yardlong beans and Thai basil samples than in other vegetables. Individually, ESBL-producing E. coli was most frequently found in Thai basil, whereas ESBL-producing $K$. pneumoniae was most frequently found in Thai yardlong beans and tomato. Moreover, ESBL-producing $E$. coli were more frequently found in Tha Sala district (4/5 isolates) than in Mueang district (1/5 isolates).

\section{Antibacterial susceptibility phenotype}

Eleven antibiotic agents of five classes (both $\beta$-lactam and non- $\beta$-lactam) were used to assess the antimicrobial susceptibility of ESBL-producing E. coli and $K$. pneumoniae isolates from 10 common edible vegetables in Southern Thailand using the disk diffusion method. All 14 isolates $(100 \%)$ were strongly sensitive to IPM, followed by AK/CN, MEM/TE, ATM, CRO, CPD, CTX/CAZ, and AMP (Table 4).

All ESBL-producing $E$. coli isolates were sensitive to not only IPM but also CN with $100 \%$ susceptibility $(5 / 5)$. The frequency of sensitivity in ESBL-producing $E$. coli isolates decreased in AK, TE/ATM, and AMP/MEM/CRO/CPD by $80 \%(4 / 5), 60 \%(3 / 5)$, and 40\% (2/5), respectively. Furthermore, only one isolate $(20 \%)$ exhibited intermediate activity against AK and CPD (Table 4). All ESBL-producing K. pneumoniae isolates were also determined to be susceptible to carbapenem IPM and MEM antibiotics $(100 \%, 9 / 9)$. These strains were also highly sensitive to TE/AK (88.89\%, 8/9), CN/ATM (77.78\%, 7/9), CRO (66.67\%, 6/9), and CTX/CAZ/CPD (55.56\%, 5/9). Intermediate sensitivity was observed against AK and CRO (1/9 isolate of each) in K. pneumoniae, representing $11.11 \%$ of the total sample (Table 4 ).

The presence of IPM and AK sensitivity against ESBL-producing E. coli and $K$. pneumoniae is promising; however, these strains were also resistant to several antibiotics (Tables 4 and 5). In total $(n=14)$, both ESBL producers (12) were found to be resistant to AMP 
241 (85.71\%), followed by CTX/CAZ (9, 64.29\%), CPD (6, 42.86\%), CRO (5, 35.71\%), ATM (4,

242

\section{$28.57 \%), \operatorname{MEM} / \mathrm{TE}(3,21.43 \%)$, and CN $(2,14.29 \%)$.}

The antibiotic-resistance profile of ESBL-producing E. coli $(\mathrm{n}=5)$ was $100 \%$ for CTX/CAZ (5/5), 60\% for AMP/MEM/CRO (3/5), and 40\% for TE/CPD/ATM (2/5). All isolates of ESBL-producing $K$. pneumoniae $(\mathrm{n}=9)$ were completely resistant to AMP $(100 \%)$, followed by CTX/CAZ/CPO (4, 44.44\%), CN/CRO/ATM (2, 22.22\%), and TE (1, 11.11\%) (Table 4).

\section{Multidrug resistance patterns}

MDR is defined as bacterial resistance to antibiotics or to at least one agent in $\geq 3$ antimicrobial classes (39). Here 7 out of $14(50 \%)$ E. coli and K. pneumoniae isolates were MDR. Of these, three were E. coli MDR isolates (60\%) and four were K. pneumoniae MDR isolates (44.44\%) (Tables 5 and 6). Interestingly, the E. coli isolate (A60301) obtained from Thai yardlong beans at a market in Mueang exhibited more resistance (63.64\%) than sensitivity $(36.36 \%)$. MDR analysis revealed that this isolate was resistant to four classes of antibiotics and was resistant to 7 out of 11 antibiotics in total. Another isolate (E50501) of ESBL-producing $E$. coli from Thai basil in Tha Sala also had an MDR profile including four antibiotic classes and was resistant to 5 out of 11 antibiotics. However, this isolate had slightly more antibiotic sensitivity $(54.55 \%)$ than resistance $(45.45 \%)$. The proportional sensitivity was similar to that of an MDR isolate (C30501). An MDR E. coli isolate derived from an MDR K. pneumoniae (A80301) was also isolated from Thai yardlong beans from Mueang district and was resistant to four classes of antibiotics (6/11) and exhibited greater resistance (54.55\%) than sensitivity (45.45\%). Although the K. pneumoniae isolates (B90101, C70101, and G70301) were obtained from several vegetables (Thai eggplant, winged bean, and cucumber, respectively) in different Mueang markets, all exhibited MDR to three classes of antibiotics (3/11), though these isolates were more susceptible $(72.73 \%)$ to eight other antibiotics than resistant (27.27\%). Consequently, these MDR patterns were more frequently found in E. coli than in K. pneumoniae isolates and were more frequently detected in samples from Mueang markets, which had the highest proportion of contamination in Thai yardlong beans (Table 6). Several of the above isolates showed MDR activity, but their sensitivities to other antibiotics ensure that the infection caused by them is still treatable.

We then characterized seven ESBL-encoding gene variants $\left(\right.$ bla $_{T E M}$, bla $_{S H V}$, bla $_{C T X-M 1}$, bla $_{C T X-M 9}$, bla $_{G E S}$, bla $_{V E B}$, and bla $\left._{P E R}\right)$ by PCR and confirmed their identity by DNA sequencing. This demonstrated that the $b l a_{S H V}$-ESBL variant $(57.14 \%)(8 / 14)$ was the most prevalent ESBLencoding variant in E. coli and K. pneumoniae (Table 7), with 4 out of 14 (28.57\%) isolates from each species containing this variant. Notably, none of the other ESBL-coding variants were detected in K. pneumoniae isolates. Furthermore, MDR genes were detected in only few of the $E$. coli isolates, with two (40\%) and one (20\%) being positive for bla $a_{T E M}$ and bla $a_{C T X-M 1}, b_{C T X-M 9}$, and $b l a_{G E S}$ variants, respectively. Moreover, $b l a_{V E B}$ or $b l a_{P E R}$ were not detected in any of the $E$. coli or K. pneumoniae isolates. 
Multiple ESBL-encoding genes were found in the E. coli isolates (2/5). A60301 and C30501 were isolated from Thai yardlong beans and winged beans from Mueang and Tha Sala markets, respectively, including two sets of three ESBL-coding gene variants: bla $a_{T E M}$, bla $_{C T X-M 1}$, $b l a_{G E S}$ and $b a_{T E M}, b l a_{S H V}, b l a_{C T X-M 9}$. Each ESBL gene variant amplified from E. coli isolates was detected by agarose gel electrophoresis (Fig. 1).

\section{Dendrogram relationship of isolated strains of $E$. coli and $K$. pneumoniae}

Phylogenetic trees of five E. coli isolates were generated by GelClust (Fig. 2A). This demonstrated that the A60301 isolate was more closely related to C30501 than to other E. coli isolates, with an identity of approximately 73\%. The G30501 isolate was probably another strain related to the E20301 and E50501 isolates (with 77\% identity). The E20301 and E50501 strains were more closely related to each other than to other isolates ( $84 \%$ identity). Phylogenetic analysis of the five $E$. coli isolates could thus be used for individual strain identification. Each isolate of $E$. coli obtained from the same vegetable or market was a different strain, but as E20301 and E50501 came from the same vegetables, they were likely to be closely related.

We also created a phylogenetic tree for all isolated $K$. pneumoniae strains, which had a wider range of genetic heterogeneities than E. coli isolates (Fig. 2B). The cluster analysis and related dendrogram revealed that five molecular genetic clusters were represented individually in each strain of $K$. pneumoniae. The H80301 strain was similar to I70201 (85\% identity), although these were the least related to any of the other stains (Fig. 2B). G70301 was related with 67\% identity to A80301/E20502 and had 55\% identity with H30301. The A80301 and E20502 isolates were shown to be of the same strain. Moreover, H30301 showed 60\% identity with C70101. The final clusters delineated the relationship between C70101 and A70201/B90101 isolates, which had 58\% identity. A70201 and B90101 were of different strains with $67 \%$ identity. The K. pneumoniae strains showed high diversity with respect to the vegetables and markets, with each isolate coming from an independent source.

\section{Discussion}

This is the first report describing the number of ESBL producers contaminating Thai basil. In this study, we determined that the highest prevalence of isolates of ESBL-producing $E$. coli and $K$. pneumoniae producers is in Thai yardlong beans and Thai basil samples, representing $8.3 \%-8.8 \%$ of all samples. Nevertheless, the prevalence of ESBL-producing $E$. coli and $K$. pneumoniae was lower when compared with that of other studies (different types and sample sizes of vegetables), with frequencies of $10.1 \%, 13.3 \%, 16.4 \%$, and $43.3 \%(12,16,22,28)$. Therefore, this may imply that the variation in the prevalence of ESBL-producing strains depends on the sample size and types of vegetables tested.

We determined that the E. coli and K. pneumoniae strains isolated in this study showed resistance to a range of antibiotics. These isolates were resistant to broad-spectrum AMP $(85.71 \%)$ and third-generation cephalosporin antibiotics, including CTX, CRO, CAZ, and CPD $(40 \%-70 \%)$. Our results are in accordance with those of a previous review by Falagas and 
321 Karageorgopoulos (2009) that showed that E. coli and $K$. pneumoniae produced high amounts of ESBL enzyme, which can hydrolyze many common antibiotics, i.e., penicillin (antibiotic class same as AMP), cephalosporins, and ATM (carbapenem), resulting in antibiotic resistance in these bacteria (2). Furthermore, Zurfluh et al. (2015) reported that 26 isolates of ESBLproducing $E$. coli and $K$. pneumoniae obtained from imported vegetables in Dominican Republic, India, Thailand, and Vietnam were resistant to AMP (100\%) and narrow-spectrum cephalosporins: cephalothin (INN) and CTX (88.3\%) (28). Kim et al. (2015) determined the antibiotic susceptibility of ESBL-producing E. coli and $K$. pneumoniae, isolated from sprout samples in South Korea, and showed these were resistant to CTX (100\%) (12). Another study showed that all ESBL-producing $E$. coli isolated from raw vegetables were completely resistant to AMP, CTX, and other antibiotics (piperacillin, cefazoline, and nalidixic acid) (29). E. coli isolated from fresh vegetables showed resistance to cephalosporins, such CTX and CAZ (92\%) (22). In our study, E. coli was most frequently resistant to cephalosporins, such as CTX and CAZ (100\%), and AMP (60\%), which was not only consistent with the above reports for isolates from raw vegetables but also for isolates from clinical specimens (60\%-62\% to cephalosporins) and healthy subjects $(72 \%$ to AMP) in low- and middle-income countries $(1,5,22,29)$. The resistance patterns of $E$. coli from different sources may be associated with each other because of transmission of resistance genes between humans and environments. Moreover, in this study, MDR patterns of E. coli $(21.43 \%)$ and $K$. pneumoniae $(28.57 \%$ ) were present in $50 \%$ of ESBLproducing isolates that shared resistance to 3-4 antibiotic classes of $\beta$-lactam antibiotics (aminopenicillin, cephalosporin, and carbapenem) and non- $\beta$-lactam antibiotics (aminoglycosides and TE). Our results correlated with those of a previously study that described MDR strains, particularly against $\beta$-lactam CTX and non- $\beta$-lactam CHL and TE, found in iceberg lettuce (27). An MDR E. coli strain that was resistant to $\beta$-lactam (AMP, INN, and CTX) and non- $\beta$-lactam (trimethoprim and TE) antibiotics was isolated from imported Thai yardlong beans in Switzerland (28). Two MDR E. coli strains isolated from sprouts were resistant to CTX, CAZ, cefepime, ATM, ciprofloxacin (CIP), and trimethoprim/sulfamethoxazole (12). We also found strong resistance to multiple antibiotic classes in E. coli, highlighting concerns of MDR. Although the presence of MDR in K. pneumoniae isolates was higher than that in E. coli isolates, other antibiotic sensitivities remained high (except for AMP). Conversely, Bhutani et al. (2015) reported major resistance to CTX (86\%) in two K. pneumoniae isolates from iceberg lettuce (27).

The K. pneumoniae strains isolated here commonly carried the bla $a_{S H V}$ variant, which was also present in several E. coli strains. However, E. coli isolates from selected vegetables seem be strong producers of ESBL enzymes via the co-existence of several ESBL-encoding genes. The $E$. coli A60301 and C30501 strains isolated from yardlong beans and winged beans carried the bla $_{T E M}$, bla $_{C T X-M 1}$, and bla $a_{G E S}$ and the bla ${ }_{T E M}$, bla $_{S H V}$, and bla $a_{C T X-M 9}$ variants, respectively. Their co-expression may result in stronger ESBL production and increased antibiotic resistance or MDR. Consequently, E. coli strains producing high levels of ESBL may be harbored in Thai yardlong beans and wing beans. However, the level of ESBL production is yet to be evaluated. 
Not surprisingly, the $b l a_{S H V}$ variant was frequently found both in E. coli and $K$. pneumoniae because this variant is a common genetic variant found in the ESBL-producing Enterobacteriaceae family $(4,28)$. $b l a_{S H V}$ and $b l a_{T E M}$ were recognized as producing ESBL and were initially reported from clinical isolates, as were the bla ${ }_{V E B}, b l a_{P E R}$, and $b l a_{G E S}$ variants, although five types of bla $_{C T X-M}$ were originally mainly found in environmental isolates (Kluyvera spp.) $(4,28)$. The relevant genes are thought to have been mobilized into conjugative plasmids, and thus transferred to pathogenic bacteria (28). Community-onset ESBL-associated infections, including urinary infection and sepsis are principally caused by E. coli having $b l a_{C T X-M}$. ESBLs (28). Therefore, the relevant genes might contribute to the presence of ESBLs in communitytransmitted infections from animal sources to humans via food chains or patient-to-patient transmission (28). Notably, in this study, the A60301 and C30501 E. coli isolates that coharbored those relevant ESBL variants may be considered as antibiotic-resistance predictors that can pass between food chains (vegetable) and undergo human transmission in the community if consumers lack good hygiene.

Carbapenems are widely regarded as the antibiotics of choice for the treatment of severe infections caused by ESBL-producing Enterobacteriaceae (4). In our study, the antibiotic susceptibility of ESBL-producing E. coli and K. pneumoniae isolates was $100 \%$ (completely resistant) to carbapenem (IPM) and $85.71 \%$ (mostly resistant) to aminoglycosides such as AK and CN. Carbapenem sensitivities similar to these have also been reported in other studies (83\% and $99.3 \%-100 \%)(22,40)$.

The prevalence of E. coli and K. pneumoniae isolates was demonstrated by the range of different strains determined using phylogenetic tree analysis. It was clearly shown that ESBLproducing $E$. coli and $K$. pneumoniae outbreaks have been problem in the food chain. However, further analysis using whole-genome sequence is essential to determine more epidemiological features of the ESBL-producing E. coli and K. pneumoniae in raw vegetables.

\section{Conclusions}

As per our findings, it was determined that retail vegetables at local markets in Nakhon Si Thammarat may be reservoirs for the spread of ESBL-producing E. coli and K. pneumoniae. This may lead to antibiotic resistance through food chain transmission if consumer hygiene is poor. Nevertheless, further investigations are necessary to understand supplementary epidemiological features of ESBL-producing E. coli and $K$. pneumoniae in raw vegetables.

\section{Acknowledgements}

The authors thank the Research Institute for Health Sciences Walailak University, School of Allied Health Sciences, Walailak University, and Department of Biomedical Sciences, Faculty of Medicine, Prince of Songkla University for providing the required laboratory instruments.

Author Contributions: C.R. and P.S. conceived and designed the experiments. C.R., S.Y., D.W., and P.SA. performed the experiments. C.R., P.S., and S.C. analyzed the data. C.R. contributed reagents, materials, and analysis tools. C.R. and S.C. wrote the manuscript. 
400 Ethics approval: This study did not include any experiments on human participants or animals. 
401

402

403

404

405

406

407

408

409

410

411

412

413

414

415

416

417

418

419

420

421

422

423

\section{References}

1. Nji E, Kazibwe J, Hambridge T, Joko CA, Larbi AA, Damptey LAO, et al. High prevalence of antibiotic resistance in commensal Escherichia coli from healthy human sources in community settings. Scientific reports. 2021;11(1):3372.

2. Falagas ME, Karageorgopoulos DE. Extended-spectrum beta-lactamase-producing organisms. The Journal of hospital infection. 2009;73(4):345-54.

3. Boonyasiri A, Tangkoskul T, Seenama C, Saiyarin J, Tiengrim S, Thamlikitkul V. Prevalence of antibiotic resistant bacteria in healthy adults, foods, food animals, and the environment in selected areas in Thailand. Pathogens and global health. 2014;108(5):235-45.

4. Pitout JD, Laupland KB. Extended-spectrum beta-lactamase-producing Enterobacteriaceae: an emerging public-health concern. The Lancet Infectious diseases. 2008;8(3):159-66.

5. Teklu DS, Negeri AA, Legese MH, Bedada TL, Woldemariam HK, Tullu KD. Extendedspectrum beta-lactamase production and multi-drug resistance among Enterobacteriaceae isolated in Addis Ababa, Ethiopia. Antimicrobial Resistance \& Infection Control. 2019;8(1):39. 6. Chong Y, Shimoda S, Shimono N. Current epidemiology, genetic evolution and clinical impact of extended-spectrum $\beta$-lactamase-producing Escherichia coli and Klebsiella pneumoniae. Infect Genet Evol. 2018;61:185-8.

7. Wu G, Day MJ, Mafura MT, Nunez-Garcia J, Fenner JJ, Sharma M, et al. Comparative analysis of ESBL-positive Escherichia coli isolates from animals and humans from the UK, The Netherlands and Germany. PLoS One. 2013;8(9):e75392.

8. Yazdi M, Nazemi A, Mirinargasi M, Jafarpour M, Sharifi S, Branch T. Genotypic versus Phenotypic methods to detect extended-spectrum beta-lactamases (ESBLs) in uropathogenic Escherichia coli. Ann Biol Res. 2012;3(5):2454-8.

9. Guenther S, Ewers C, Wieler LH. Extended-Spectrum Beta-Lactamases Producing E. coli in Wildlife, yet Another Form of Environmental Pollution? Front Microbiol. 2011;2:246.

10. Reuland EA, Al Naiemi N, Raadsen SA, Savelkoul PHM, Kluytmans JAJW, Vandenbroucke-Grauls CMJE. Prevalence of ESBL-producing Enterobacteriaceae in raw vegetables. Eur J Clin Microbiol Infect Dis. 2014;33(10):1843-6.

11. Brookie KL, Best GI, Conner TS. Intake of Raw Fruits and Vegetables Is Associated With Better Mental Health Than Intake of Processed Fruits and Vegetables. Front Psychol. 2018;9:487-.

\section{Kim HS, Chon JW, Kim YJ, Kim DH, Kim MS, Seo KH. Prevalence and} characterization of extended-spectrum-beta-lactamase-producing Escherichia coli and Klebsiella pneumoniae in ready-to-eat vegetables. International journal of food microbiology. 2015;207:836.

13. Mritunjay SK, Kumar V. A study on prevalence of microbial contamination on the surface of raw salad vegetables. 3 Biotech. 2017;7(1):13.

14. Saksena R, Malik M, Gaind R. Bacterial contamination and prevalence of antimicrobial resistance phenotypes in raw fruits and vegetables sold in Delhi, India. Journal of Food Safety. 2020;40(1):e12739.

15. Blaak H, van Hoek AH, Veenman C, Docters van Leeuwen AE, Lynch G, van Overbeek WM, et al. Extended spectrum ss-lactamase- and constitutively AmpC-producing

Enterobacteriaceae on fresh produce and in the agricultural environment. International journal of food microbiology. 2014;168-169:8-16. 
446 16. Richter L, Du Plessis EM, Duvenage S, Korsten L. Occurrence, Identification, and 447 Antimicrobial Resistance Profiles of Extended-Spectrum and AmpC $\beta$-Lactamase-Producing 448 Enterobacteriaceae from Fresh Vegetables Retailed in Gauteng Province, South Africa.

449 Foodborne Pathogens and Disease. 2019;16(6):421-7.

450 17. Eibach D, Dekker D, Gyau Boahen K, Wiafe Akenten C, Sarpong N, Belmar Campos C, 451 et al. Extended-spectrum beta-lactamase-producing Escherichia coli and Klebsiella pneumoniae 452 in local and imported poultry meat in Ghana. Veterinary microbiology. 2018;217:7-12.

453 18. Ryu SH, Lee JH, Park SH, Song MO, Park SH, Jung HW, et al. Antimicrobial resistance 454 profiles among Escherichia coli strains isolated from commercial and cooked foods.

455 International journal of food microbiology. 2012;159(3):263-6.

456 19. Le QP, Ueda S, Nguyen TN, Dao TV, Van Hoang TA, Tran TT, et al. Characteristics of

457 Extended-Spectrum beta-Lactamase-Producing Escherichia coli in Retail Meats and Shrimp at a 458 Local Market in Vietnam. Foodborne Pathog Dis. 2015;12(8):719-25.

459 20. Abayneh M, Tesfaw G, Woldemichael K, Yohannis M, Abdissa A. Assessment of 460 extended-spectrum beta-lactamase (ESBLs) - producing Escherichia coli from minced meat of 461 cattle and swab samples and hygienic status of meat retailer shops in Jimma town, Southwest 462 Ethiopia. BMC infectious diseases. 2019;19(1):897.

463 21. Montso KP, Dlamini SB, Kumar A, Ateba CN. Antimicrobial Resistance Factors of 464 Extended-Spectrum Beta-Lactamases Producing Escherichia coli and Klebsiella pneumoniae 465 Isolated from Cattle Farms and Raw Beef in North-West Province, South Africa. BioMed 466 Research International. 2019;2019:4318306.

467 22. Ye Q, Wu Q, Zhang S, Zhang J, Yang G, Wang J, et al. Characterization of Extended468 Spectrum $\beta$-Lactamase-Producing Enterobacteriaceae From Retail Food in China. Frontiers in 469 Microbiology. 2018;9(1709).

470 23. Tekiner sH, Özp1 nar H. Occurrence and characteristics of extended spectrum beta471 lactamases-producing Enterobacteriaceae from foods of animal origin. Brazilian Journal of 472 Microbiology. 2016;47:444-51.

473 24. Hiroi M, Yamazaki F, Harada T, Takahashi N, Iida N, Noda Y, et al. Prevalence of extended-spectrum beta-lactamase-producing Escherichia coli and Klebsiella pneumoniae in food-producing animals. The Journal of veterinary medical science. 2012;74(2):189-95. 25. S R.

26. Kaesbohrer A, Bakran-Lebl K, Irrgang A, Fischer J, Kämpf P, Schiffmann A, et al. Diversity in prevalence and characteristics of ESBL/pAmpC producing E. coli in food in Germany. Veterinary microbiology. 2019;233:52-60.

27. Bhutani N, Muraleedharan C, Talreja D, Rana SW, Walia S, Kumar A, et al. Occurrence of Multidrug Resistant Extended Spectrum Beta-Lactamase-Producing Bacteria on Iceberg Lettuce Retailed for Human Consumption. BioMed Research International. 2015;2015:547547. 28. Zurfluh K, Nüesch-Inderbinen M, Morach M, Zihler Berner A, Hächler H, Stephan R. Extended-Spectrum- $\beta$-Lactamase-Producing Enterobacteriaceae Isolated from Vegetables Imported from the Dominican Republic, India, Thailand, and Vietnam. Applied and Environmental Microbiology. 2015;81(9):3115.

29. Song J, Oh S-S, Kim J, Shin J. Extended-spectrum $\beta$-lactamase-producing Escherichia coli isolated from raw vegetables in South Korea. Scientific reports. 2020;10(1):19721. 30. Bubpamala J, Khuntayaporn P, Thirapanmethee K, Montakantikul P, Santanirand P, Chomnawang MT. Phenotypic and genotypic characterizations of extended-spectrum beta- 
491

492

493

494

495

lactamase-producing Escherichia coli in Thailand. Infection and drug resistance. 2018;11:21517.

31. CLSI. Methods for antimicrobial susceptibility testing of anaerobic bacteria.. 29 ed. PA, USA2019.

32. Seenama C, Thamlikitkul V, Ratthawongjirakul P. Multilocus sequence typing and bla (ESBL) characterization of extended-spectrum beta-lactamase-producing Escherichia coli isolated from healthy humans and swine in Northern Thailand. Infection and drug resistance. 2019;12:2201-14.

33. Le QP, Ueda S, Nguyen TN, Dao TV, Van Hoang TA, Tran TT, et al. Characteristics of Extended-Spectrum $\beta$-Lactamase-Producing Escherichia coli in Retail Meats and Shrimp at a Local Market in Vietnam. Foodborne Pathog Dis. 2015;12(8):719-25.

34. Bubpamala J, Khuntayaporn P, Thirapanmethee K, Montakantikul P, Santanirand P, Chomnawang MT. Phenotypic and genotypic characterizations of extended-spectrum betalactamase-producing Escherichia coli in Thailand. Infect Drug Resist. 2018;11:2151-7. 35. Han SK, Shin MS, Park HE, Kim SY, Lee WK. Screening of bacteriocin-producing Enterococcus faecalis strains for antagonistic activities against Clostridium perfringens. Korean J Food Sci Anim Resour. 2014;34(5):614-21.

36. Versalovic J, Koeuth T, Lupski JR. Distribution of repetitive DNA sequences in eubacteria and application to fingerprinting of bacterial genomes. Nucleic acids research. 1991;19(24):6823-31.

37. Fox JT, Renter DG, Sanderson MW, Thomson DU, Lechtenberg KF, Nagaraja TG. Evaluation of Culture Methods To Identify Bovine Feces with High Concentrations of Escherichia coli O157. Applied and Environmental Microbiology. 2007;73(16):5253. 38. Ranjbar R, Tabatabaee A, Behzadi P, Kheiri R. Enterobacterial Repetitive Intergenic Consensus Polymerase Chain Reaction (ERIC-PCR) Genotyping of Escherichia coli Strains Isolated from Different Animal Stool Specimens. Iranian journal of pathology. 2017;12(1):2534.

39. Magiorakos AP, Srinivasan A, Carey RB, Carmeli Y, Falagas ME, Giske CG, et al. Multidrug-resistant, extensively drug-resistant and pandrug-resistant bacteria: an international expert proposal for interim standard definitions for acquired resistance. Clinical microbiology and infection : the official publication of the European Society of Clinical Microbiology and Infectious Diseases. 2012;18(3):268-81.

40. Devrim I, Gulfidan G, Gunay İ, Agın H, Güven B, Yılmazer MM, et al. Comparison of in vitro activity of ertapenem with other carbapenems against extended-spectrum beta-lactamaseproducing Escherichia coli and Kleibsella species isolated in a tertiary children's hospital. Expert Opinion on Pharmacotherapy. 2011;12(6):845-9. 


\section{Figure 1}

A $1.5 \%(w / v)$ agarose gel image showing the ESBL-encoding genes amplified from E. coli isolates isolated from vegetables using PCR method.

Figure 1. A 1.5\% (w/v) agarose gel image showing the ESBL-encoding genes amplified from E. coli isolates isolated from vegetables using PCR method. Lane $M=100$ bp DNA Ladder, Lane $1=$ TEM gene fragments amplified from E. coli A60301 isolates, Lane $2=S H V$ gene fragments amplified from $E$. coli G3051 isolates, Lane $3=$ GES gene fragments amplified from E. coli A6031 isolates, Lane $4=C T X-M 9$ gene fragments amplified from E. coli C30501 isolates, Lane $5=C T X-M 1$ gene fragments amplified from E. coli A60301 isolates, and Lane $\mathrm{NC}=$ Negative control. 


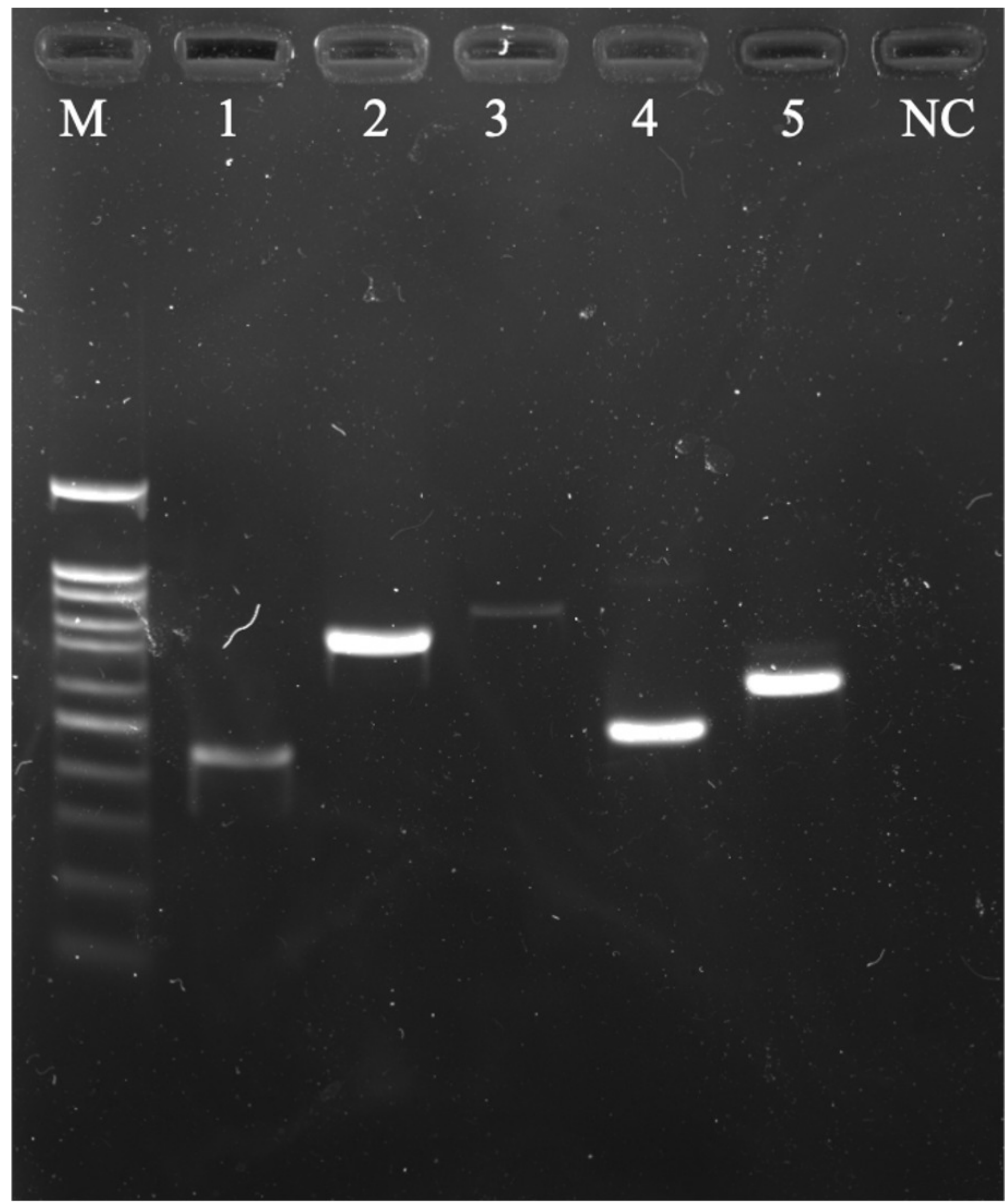




\section{Figure 2}

ERIC-PCR profiles of (A) ESBL-producing E. coli isolates and (B) ESBL-producing $K$. pneumoniae isolates from raw vegetables.

Figure 2. ERIC-PCR profiles of (A) ESBL-producing E. coli isolates and (B) ESBL-producing $K$. pneumoniae isolates from raw vegetables. A dendrogram was generated from the ERIC-PCR typing of 5 ESBL-producing E. coli and $9 \mathrm{~K}$. pneumoniae isolates. The analysis was performed using BioNumerics fingerprint data software v7.1 and the unweighted pair group method with arithmetic means (UPGMA) clustering method and the dice similarity coefficient with $1 \%$ optimization and $1.5 \%$ position tolerance. EC, E. coli; KP, K. pneumoniae 
A.

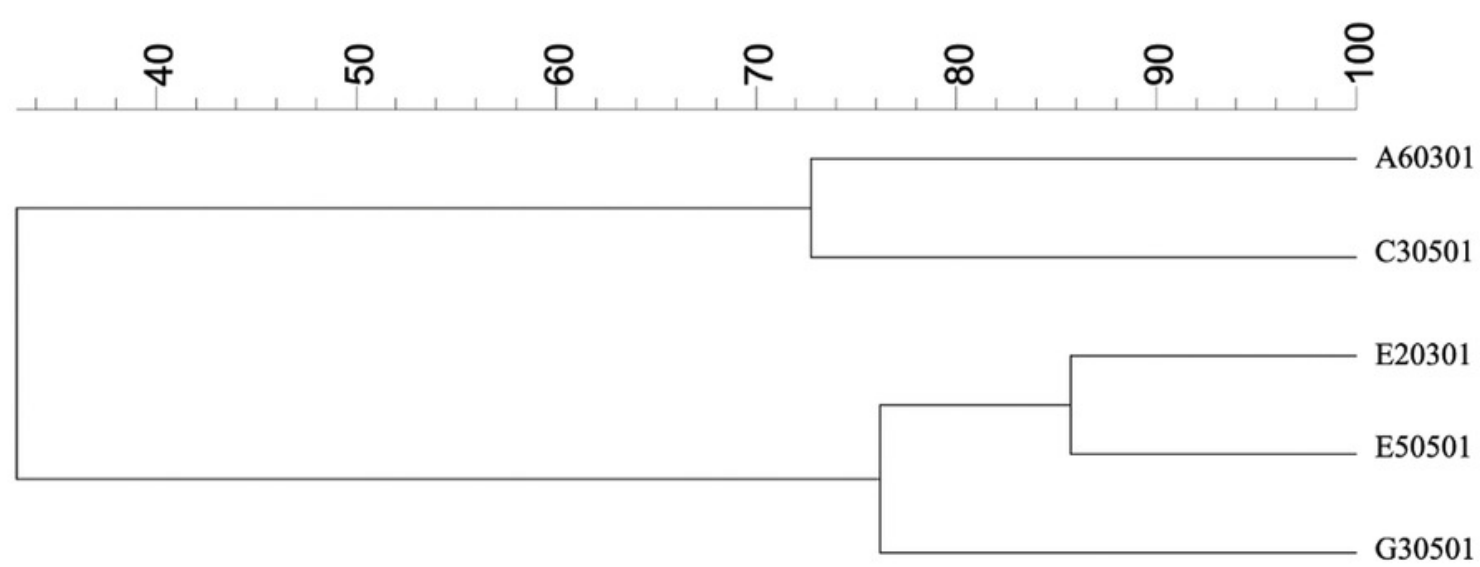

B.

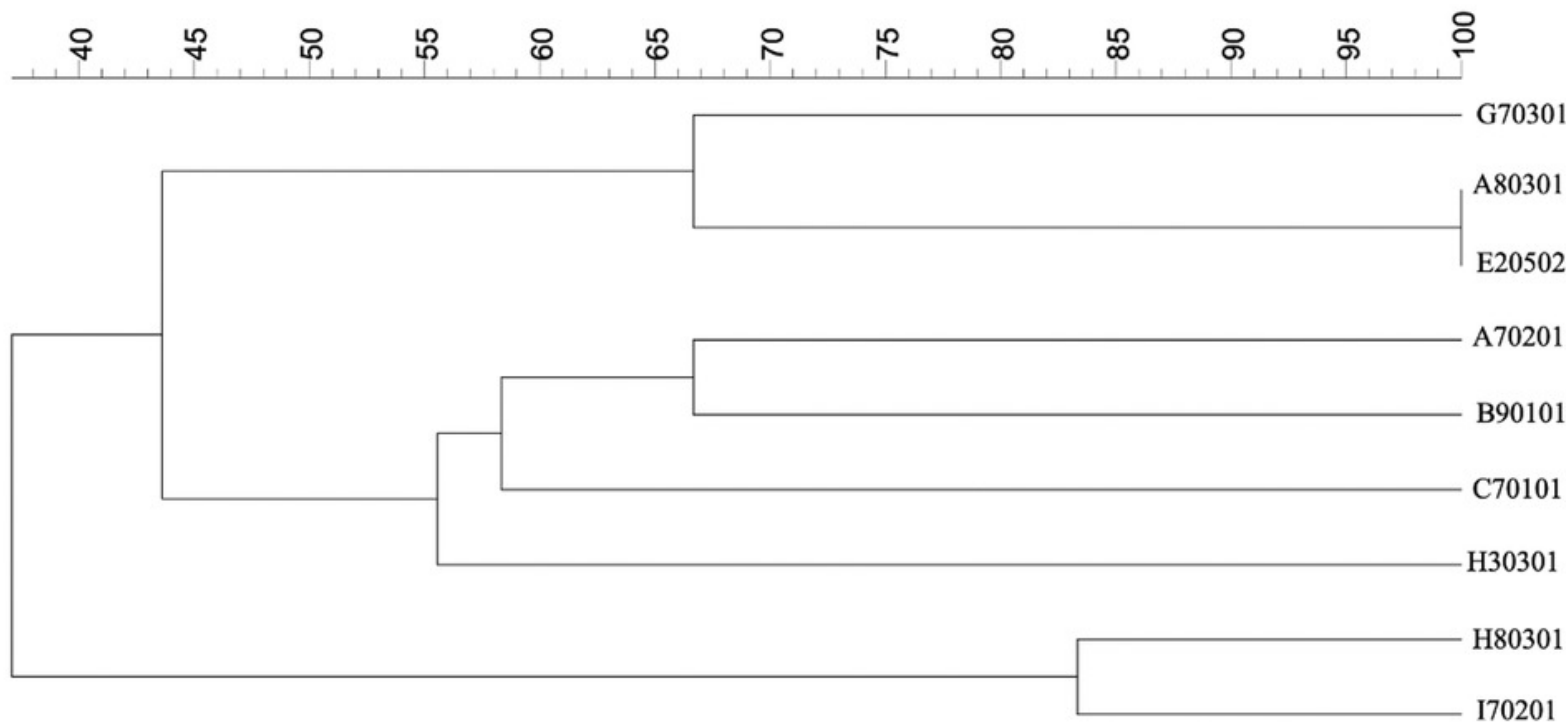




\section{Table 1 (on next page)}

PCR primer designs and their conditions for gene amplifications

PCR primer designs and their conditions for gene amplifications 
Table 1. PCR primer designs and their conditions for gene amplifications

\begin{tabular}{|c|c|c|c|c|c|c|c|c|c|c|}
\hline \multirow[b]{2}{*}{ Reference } & \multirow[b]{2}{*}{ Genes } & \multirow[b]{2}{*}{$\begin{array}{l}\text { Primer } \\
\text { names }\end{array}$} & \multirow[b]{2}{*}{ Primer sequences } & \multirow[b]{2}{*}{$\begin{array}{l}\text { Product size } \\
\text { (bp) }\end{array}$} & \multicolumn{2}{|c|}{ Denature } & \multicolumn{2}{|c|}{ Annealing } & \multicolumn{2}{|c|}{ Extension } \\
\hline & & & & & $\begin{array}{c}\text { Tem } \\
\mathbf{p} \\
\left({ }^{\circ} \mathrm{C}\right)\end{array}$ & $\begin{array}{c}\text { Time } \\
\text { (s) }\end{array}$ & $\begin{array}{c}\text { Tem } \\
\mathbf{p} \\
\left({ }^{\circ} \mathrm{C}\right)\end{array}$ & $\begin{array}{l}\text { Time } \\
\text { (s) }\end{array}$ & $\begin{array}{c}\text { Tem } \\
\mathbf{p} \\
\left({ }^{\circ} \mathrm{C}\right)\end{array}$ & $\begin{array}{c}\text { Time } \\
\text { (s) }\end{array}$ \\
\hline \multirow{4}{*}{$\begin{array}{l}\text { Le, Q. P., et } \\
\text { al. } 2015\end{array}$} & $b^{\prime} a_{C T X}$ & Ctxm1-115F & GAATTAGAGCGGCAGTCGGG & 588 & \multirow{4}{*}{95} & \multirow{4}{*}{30} & \multirow{4}{*}{60} & \multirow{4}{*}{90} & \multirow{4}{*}{72} & \multirow{4}{*}{90} \\
\hline & $M-1$ & Ctxm1-702R & CACAACCCAGGAAGCAGGC & & & & & & & \\
\hline & $b / a_{C T X-}$ & Ctxm9-16F & GTGCAACGGATGATGTTCGC & 475 & & & & & & \\
\hline & $M-9$ & Ctxm9-490R & GAAACGTCTCATCGCCGATC & & & & & & & \\
\hline \multirow{4}{*}{$\begin{array}{l}\text { Seenama, } \\
\text { C., et al. } \\
2019\end{array}$} & \multirow{2}{*}{ bla $_{T E M}$} & TEM-164.SE & TCGCCGCATACACTATTCTCAGAATGA & 445 & \multirow{4}{*}{94} & \multirow{4}{*}{30} & \multirow{4}{*}{60} & \multirow{4}{*}{40} & \multirow{4}{*}{72} & \multirow{4}{*}{90} \\
\hline & & TEM-165.AS & ACGCTCACCGGCTCCAGATTTAT & & & & & & & \\
\hline & \multirow{2}{*}{$b l a_{S H V}$} & SHV.SE & ATGCGTTATATTCGCCTGTG & 747 & & & & & & \\
\hline & & SHV.AS & TGCTTTGTTATTCGGGCCAA & & & & & & & \\
\hline \multirow{6}{*}{$\begin{array}{l}\text { Bubpamala } \\
\text {, J., et al. } \\
2018\end{array}$} & \multirow{2}{*}{$b l a_{G E S}$} & GES-F & TAC TGG CAG SGA TCG CTC AC & 838 & \multirow{6}{*}{96} & \multirow{6}{*}{30} & \multirow{2}{*}{62} & \multirow{2}{*}{90} & \multirow{6}{*}{72} & \multirow{6}{*}{30} \\
\hline & & GES-F & TTG TCC GTG CTC AGG ATG AG & & & & & & & \\
\hline & \multirow{2}{*}{$b a_{V E B}$} & VEB-F & GCC AGA ATA GGA GTA GCA AT & 703 & & & 58 & an & & \\
\hline & & VEB-R & TGG ACT CTG CAA CAA ATA CG & & & & 58 & 90 & & \\
\hline & \multirow{2}{*}{$b l a_{P E R}$} & PER-F & CTC AGC GCA ATC CCC ACT GT & 851 & & & \multirow{2}{*}{62} & \multirow{2}{*}{90} & & \\
\hline & & PER-R & TTG GGC TTA GGG CAG AAA GCT & & & & & & & \\
\hline
\end{tabular}

2 


\section{Table 2 (on next page)}

Summary of the raw vegetables and Prevalence of ESBL-producing E. coli and $K$. pneumoniae isolated from raw vegetables in retail markets in Mueang and Tha Sala districts, Nakhon Si Thammarat, Thailand.

Summary of the raw vegetables and Prevalence of ESBL-producing E. coli and K. pneumoniae isolated from raw vegetables in retail markets in Mueang and Tha Sala districts, Nakhon Si Thammarat, Thailand. 
Table 2. Summary of the raw vegetables and Prevalence of ESBL-producing $E$. coli and $K$. pneumoniae isolated from raw vegetables in retail markets in Mueang and Tha Sala districts, Nakhon Si Thammarat, Thailand.

\begin{tabular}{cccccc}
\hline \multirow{2}{*}{ Order } & \multirow{2}{*}{ Origin } & \multirow{2}{*}{} & \multicolumn{3}{c}{ No. of ESBL producer (\%) } \\
\cline { 4 - 6 } & & & $\mathbf{E C}$ & $\mathbf{K P}$ & Total \\
\hline $\mathrm{A}$ & Thai yardlong beans & 34 & $1(2.9)$ & $2(5.9)$ & $3(8.8)$ \\
\hline $\mathrm{B}$ & Thai eggplant & 44 & 0 & $1(2.3)$ & $1(2.3)$ \\
\hline $\mathrm{C}$ & Winged beans & 25 & $1(4.0)$ & $1(4.0)$ & $2(8.0)$ \\
\hline $\mathrm{D}$ & Young cashew leaves & 20 & 0 & 0 & 0 \\
\hline $\mathrm{E}$ & Thai basil & 36 & $2(5.6)$ & $1(2.8)$ & $3(8.3)$ \\
\hline $\mathrm{F}$ & Cabbage & 21 & 0 & 0 & 0 \\
\hline $\mathrm{G}$ & Cucumber & 36 & $1(2.8)$ & $1(2.8)$ & $2(5.6)$ \\
\hline $\mathrm{H}$ & Tomato & 31 & 0 & $2(6.5)$ & $2(6.5)$ \\
\hline $\mathrm{I}$ & Long coriander & 32 & 0 & $1(3.1)$ & $1(3.1)$ \\
\hline $\mathrm{J}$ & Lettuce & 26 & 0 & 0 & 0 \\
\hline & Total & 305 & $5(1.6 \%)$ & $9(3.0 \%)$ & $14(4.6)$ \\
\hline
\end{tabular}

Abbreviations: ESBL, extended-spectrum $\beta$-lactamase; EC, E. coli; KP, K. pneumoniae 


\section{Table 3 (on next page)}

Summary of the retail markets and Prevalence of ESBL-producing E. coli and $K$. pneumoniae isolated from raw vegetables in retail markets in Mueang and Tha Sala districts, Nakhon Si Thammarat, Thailand.

Summary of the retail markets and Prevalence of ESBL-producing E. coli and $K$. pneumoniae isolated from raw vegetables in retail markets in Mueang and Tha Sala districts, Nakhon Si Thammarat, Thailand. 
Table 3. Summary of the retail markets and Prevalence of ESBL-producing E. coli and K. pneumoniae isolated from raw vegetables in retail markets in Mueang and Tha Sala districts, Nakhon Si Thammarat, Thailand.

\begin{tabular}{cccccc}
\hline \multirow{2}{*}{ Order } & Origin & $\mathbf{n}$ & \multicolumn{2}{c}{ No. of ESBL producer (\%) } \\
\cline { 5 - 6 } & & EC & \multicolumn{2}{c}{ KP } & Total \\
\hline 1 & Mor Chuan Fresh Market (Tha Sala M1) & 8 & 0 & 0 & 0 \\
\hline 2 & Nab Anusorn Fresh Market (Tha Sala M2) & 38 & $1(2.6)$ & $1(2.6)$ & $2(5.3)$ \\
\hline 3 & Wat Node Market (Tha Sala M3) & 58 & $2(3.5)$ & $1(1.7)$ & 0 \\
\hline 4 & Thursday Flea Market (Tha Sala M4) & 53 & 0 & 0 & $1(2.6)$ \\
\hline 5 & Sunday Flea market (Tha Sala M5) & 38 & $1(2.6)$ & 0 & $1(2.4)$ \\
\hline 6 & Thapae Fresh Market (Mueang M1) & 42 & $1(2.4)$ & $4(19.0)$ & $4(19.0)$ \\
\hline 7 & Khu Khwang Municipal Market (Mueang M2) & 21 & 0 & $2(5.4)$ & $2(5.4)$ \\
\hline 8 & Tha Ma Fresh Market (Mueang M3) & 37 & 0 & $1(10.0)$ & $1(10.0)$ \\
\hline 9 & Hua It Fresh Market (Mueang M4) & 10 & 0 & $9(3.0 \%)$ & $14(4.6)$ \\
\hline
\end{tabular}

Abbreviations: ESBL, extended-spectrum $\beta$-lactamase; EC, E. coli; KP, K. pneumoniae 


\section{Table 4 (on next page)}

Antimicrobial susceptibility test in ESBL-producing E.coli and K.pneumoniae

Antimicrobial susceptibility test in ESBL-producing E.coli and K.pneumoniae 
Table 4. Antimicrobial susceptibility test in ESBL-producing E.coli and K.pneumoniae

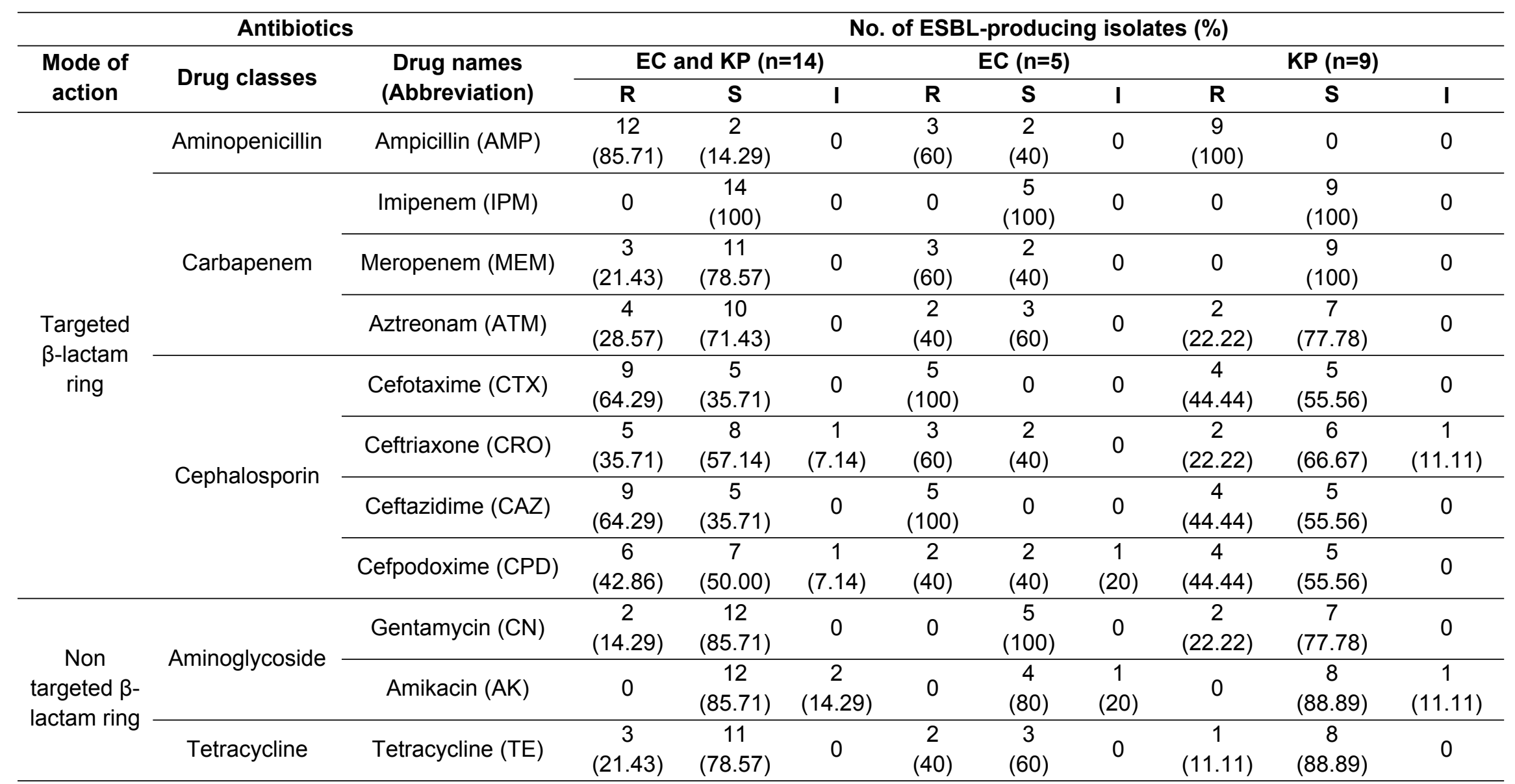




\section{Table 5 (on next page)}

Antimicrobial susceptibility test against ESBL-producing E. coli and K. pneumoniae isolates

Antimicrobial susceptibility test against ESBL-producing $E$. coli and $K$. pneumoniae isolates 
1 Table 5. Antimicrobial susceptibility test against ESBL-producing E. coli and K. pneumoniae isolates

\begin{tabular}{|c|c|c|c|c|c|c|c|c|c|c|c|}
\hline \multirow{4}{*}{$\begin{array}{l}\text { ESBL- } \\
\text { producin } \\
\mathbf{g} \\
\text { isolates }\end{array}$} & \multicolumn{11}{|c|}{ Antibiotics classes and antibiotics } \\
\hline & \multirow{3}{*}{$\frac{\text { Aminopenicillin }}{c \begin{array}{c}\text { Ampicillin } \\
\text { (AMP) }\end{array}}$} & \multicolumn{6}{|c|}{ Targeted $\beta$-lactam ring } & & \multicolumn{3}{|c|}{ Non-targeted $\beta$-lactam ring } \\
\hline & & \multicolumn{3}{|c|}{ Carbapenem } & \multicolumn{4}{|c|}{ Cephalosporin } & \multicolumn{2}{|c|}{ Aminoglycoside } & \multirow{2}{*}{$\begin{array}{c}\text { Tetracyclin } \\
\text { e } \\
\text { Tetracyclin } \\
\text { e } \\
\text { (TE) }\end{array}$} \\
\hline & & $\begin{array}{c}\text { Imipene } \\
\text { m } \\
\text { (IPM) }\end{array}$ & $\begin{array}{c}\text { Meropene } \\
\text { m } \\
\text { (MEM) }\end{array}$ & $\begin{array}{c}\text { Aztreona } \\
\mathrm{m} \\
\text { (ATM) }\end{array}$ & $\begin{array}{c}\text { Cefotaxim } \\
\text { e } \\
\text { (CTX) }\end{array}$ & $\begin{array}{c}\text { Ceftriaxon } \\
\text { e } \\
\text { (CRO) }\end{array}$ & $\begin{array}{l}\text { Ceftazidime } \\
\text { (CAZ) }\end{array}$ & $\begin{array}{c}\text { Cefpodoxim } \\
\text { e } \\
\text { (CPD) }\end{array}$ & $\begin{array}{c}\text { Gentamici } \\
n \\
\text { (CN) }\end{array}$ & $\begin{array}{c}\text { Amikaci } \\
n \\
(A K)\end{array}$ & \\
\hline \multicolumn{12}{|c|}{$\mathrm{EC}$} \\
\hline A60301 & $\mathrm{R}$ & $\mathrm{S}$ & $\mathrm{R}$ & $\mathrm{S}$ & $\mathrm{R}$ & $\mathrm{R}$ & $\mathrm{R}$ & $\mathrm{R}$ & $\mathrm{S}$ & $\mathrm{S}$ & $\mathrm{R}$ \\
\hline C30501 & $\mathrm{R}$ & $S$ & $\mathrm{R}$ & $\mathrm{R}$ & $\mathrm{R}$ & $\mathrm{S}$ & $\mathrm{R}$ & $S$ & $\mathrm{~S}$ & $S$ & $S$ \\
\hline E20301 & $\mathrm{S}$ & $S$ & $\mathrm{~S}$ & $\mathrm{R}$ & $\mathrm{R}$ & $\mathrm{R}$ & $\mathrm{R}$ & $\mathrm{R}$ & $S$ & $S$ & $S$ \\
\hline E50501 & $\mathrm{R}$ & $S$ & $\mathrm{R}$ & $S$ & $\mathrm{R}$ & $S$ & $\mathrm{R}$ & $S$ & $S$ & $S$ & $\mathrm{R}$ \\
\hline G30501 & $S$ & $S$ & $S$ & $S$ & $\mathrm{R}$ & $\mathrm{R}$ & $\mathrm{R}$ & I & $S$ & $\mathrm{I}$ & $S$ \\
\hline \multicolumn{12}{|c|}{$\mathrm{KP}$} \\
\hline A70201 & $\mathrm{R}$ & $S$ & $S$ & $S$ & $S$ & $S$ & $\mathrm{R}$ & $S$ & $S$ & 1 & $S$ \\
\hline A80301 & $\mathrm{R}$ & $S$ & $S$ & $S$ & $\mathrm{R}$ & $\mathrm{R}$ & $\mathrm{R}$ & $\mathrm{R}$ & $R$ & $S$ & $S$ \\
\hline B90101 & $\mathrm{R}$ & $S$ & $S$ & $S$ & $S$ & $S$ & $S$ & $\mathrm{R}$ & $S$ & $S$ & $\mathrm{R}$ \\
\hline C70101 & $\mathrm{R}$ & $S$ & $S$ & $\mathrm{R}$ & $S$ & $S$ & $S$ & $S$ & $\mathrm{R}$ & $S$ & $S$ \\
\hline E20502 & $\mathrm{R}$ & $S$ & $S$ & $S$ & $\mathrm{R}$ & I & $S$ & $\mathrm{R}$ & $S$ & $S$ & $S$ \\
\hline G70301 & $\mathrm{R}$ & $S$ & $S$ & $\mathrm{R}$ & $\mathrm{R}$ & $S$ & $S$ & $S$ & $S$ & $S$ & $S$ \\
\hline H30301 & $\mathrm{R}$ & $S$ & $S$ & $S$ & $S$ & $S$ & $\mathrm{R}$ & $\mathrm{R}$ & $S$ & $S$ & $S$ \\
\hline $\mathrm{H} 80301$ & $\mathrm{R}$ & $S$ & $S$ & $S$ & $S$ & $S$ & $\mathrm{R}$ & $S$ & $S$ & $S$ & $S$ \\
\hline 170201 & $\mathrm{R}$ & $S$ & $S$ & $S$ & $\mathrm{R}$ & $\mathrm{R}$ & $S$ & $S$ & $S$ & $S$ & $S$ \\
\hline
\end{tabular}

2 Abbreviations: ESBL, extended-spectrum ß-lactamase; EC, E. coli; KP, K. pneumoniae; R, resistance; S, Susceptible; I, intermediate 


\section{Table 6(on next page)}

Multidrug resistance patterns of ESBL-producing $E$. coli and $K$. pneumoniae isolates

Multidrug resistance patterns of ESBL-producing E. coli and $K$. pneumoniae isolates 
Table 6. Multidrug resistance patterns of ESBL-producing E. coli and K. pneumoniae isolates

\begin{tabular}{|c|c|c|c|c|c|c|}
\hline \multirow{3}{*}{ ESBL-producing isolates } & \multirow{2}{*}{\multicolumn{3}{|c|}{$\begin{array}{c}\text { No. of antibiotics activity }(\%) \\
\text { Antibiotics }(n=11)\end{array}$}} & \multirow{3}{*}{ MDR patterns } & \multirow{3}{*}{$\begin{array}{l}\text { No. of resistant } \\
\text { antibiotics } \\
\text { classes }\end{array}$} & \multirow{3}{*}{$\begin{array}{c}\text { MDR } \\
\text { activity }\end{array}$} \\
\hline & & & & & & \\
\hline & $\mathbf{R}$ & $\mathbf{S}$ & I & & & \\
\hline \multicolumn{7}{|c|}{$\mathrm{EC}(\mathrm{n}=5)$} \\
\hline A60301 & $7(63.64)$ & $4(36.36)$ & 0 & AMP, MEM, CTX, CRO, CAZ, CPD, TE & 4 & + \\
\hline C30501 & $5(45.45)$ & $6(54.55)$ & 0 & AMP, MEM, ATM, CTX, CAZ & 3 & + \\
\hline E20301 & $5(45.45)$ & $6(54.55)$ & 0 & ATM, CTX, CRO, CAZ, CPD & 2 & - \\
\hline E50501 & $5(45.45)$ & $6(54.55)$ & 0 & AMP, MEM, CTX, CAZ, TE & 4 & + \\
\hline G30501 & $3(27.27)$ & $6(54.55)$ & $2(18.18)$ & CTX, CRO, CAZ & 1 & - \\
\hline \multicolumn{7}{|c|}{$K P(n=9)$} \\
\hline A70201 & $2(18.18)$ & $8(72.73)$ & $1(9.09)$ & AMP, CAZ & 2 & - \\
\hline A80301 & $6(54.55)$ & $5(45.45)$ & 0 & AMP, CN, CTX, CRO, CAZ, CPD & 3 & + \\
\hline B90101 & $3(27.27)$ & $8(72.73)$ & 0 & AMP, CPD, TE & 3 & + \\
\hline C70101 & $3(27.27)$ & $8(72.73)$ & 0 & AMP, CN, ATM, & 3 & + \\
\hline E20502 & $3(27.27)$ & $7(63.64)$ & $1(9.09)$ & AMP, CTX, CPD & 2 & - \\
\hline G70301 & $3(27.27)$ & $8(72.73)$ & 0 & AMP, ATM, CTX & 3 & + \\
\hline H30301 & $3(27.27)$ & $8(72.73)$ & 0 & AMP, CAZ, CPD & 2 & - \\
\hline $\mathrm{H} 80301$ & $2(18.18)$ & $9(81.82)$ & 0 & AMP, CAZ & 2 & - \\
\hline 170201 & $3(27.27)$ & $8(72.73)$ & 0 & AMP, CTX, CRO & 2 & - \\
\hline
\end{tabular}


Table 7 (on next page)

ESBL-encoding genes of $E$. coli and $K$. pneumoniae isolates

ESBL-encoding genes of $E$. coli and $K$. pneumoniae isolates 
1 Table 7. ESBL-encoding genes of $E$. coli and $K$. pneumoniae isolates

\begin{tabular}{|c|c|c|c|c|c|c|c|}
\hline \multirow{2}{*}{ ESBL-producing isolates } & \multicolumn{7}{|c|}{ ESBL-coding genes (\%) } \\
\hline & bla $_{T E M}$ & $b_{\text {la }}$ & bla $_{C T X-M 1}$ & bla $a_{C T X-M 9}$ & $b / a_{G E S}$ & $b \mathbf{a}_{V E B}$ & bla $_{P E R}$ \\
\hline \multicolumn{8}{|l|}{$\mathrm{EC}(\mathrm{n}=5)$} \\
\hline A60301 & + & - & + &.- & + & - & - \\
\hline C30501 & + & + & - & + & - & - & - \\
\hline E20301 & - & + & - & - & - & - & - \\
\hline E50501 & - & + & - & - & - & - & - \\
\hline G30501 & - & + & - & - & - & - & - \\
\hline Total EC & $2(40)$ & $4(80)$ & & $1(20)$ & & 0 & 0 \\
\hline \multicolumn{8}{|l|}{$K P(n=9)$} \\
\hline A70201 & - & + & - & - & - & - & - \\
\hline A80301 & - & - & - & - & - & - & - \\
\hline B90101 & - & + & - & - & - & - & - \\
\hline C70101 & - & - & - & - & - & - & - \\
\hline E20502 & - & - & - & - & - & - & - \\
\hline G70301 & - & + & - & - & - & - & - \\
\hline H30301 & - & - & - & - & - & - & - \\
\hline $\mathrm{H} 80301$ & - & + & - & - & - & - & - \\
\hline 170201 & - & - & - & - & - & - & - \\
\hline Total KP & 0 & $4(44.44)$ & 0 & 0 & 0 & 0 & 0 \\
\hline Total EC and KP $(n=14)$ & $2(14.29)$ & $8(57.14)$ & & $1(7.14)$ & & 0 & 0 \\
\hline
\end{tabular}

2 Abbreviations: ESBL, extended-spectrum $\beta$-lactamase; EC, E. coli; KP, K. pneumoniae; +, positive; -, negative 